(2) Open Access Full Text Article

\title{
Association Among Lipid Accumulation Product, Chinese Visceral Obesity Index and Diabetic Retinopathy in Patients with Type 2 Diabetes: A Cross-Sectional Study
}

\section{Xin $\mathrm{Li}^{*}$ \\ Hui-Yao Li* \\ Zi-Wei Yu \\ Yi-Tong Zhang \\ Xue-Wei Tong \\ Xin-Yuan Gao $\mathbb{D}$}

The First Affiliated Hospital of Harbin Medical University, Harbin, Heilongjiang, I5000I, People's Republic of China

*These authors contributed equally to this work
Correspondence: Xin-Yuan Gao Department of Endocrinology, The First Affiliated Hospital of Harbin Medical University, Harbin, Heilongjiang, I5000I, People's Republic of China Tel +86 1390451700।

Email15369337970@I63.com
Background and Aim: Obesity often coexists with diabetes, especially abdominal obesity, recognized as a risk factor for diabetic complications. Diabetic retinopathy (DR), as one of the most common microvascular complications of diabetes, may be associated with these indices. Lipid accumulation product (LAP) and Chinese visceral obesity index (CVAI) are novel visceral obesity indicators, which have been proven to be an influential factor predicting type 2 diabetes (T2DM). However, the correlation among LAP, CVAI, and DR still lacks systematic research in T2DM. The study aimed to explore the relationship among LAP, CVAI levels in different DR stages of T2DM patients and the diagnostic efficacy of LAP and CVAI for DR.

Methods: A total of 263 participants were recruited in this cross-sectional study. We enrolled 169 patients with T2DM, divided into the non-DR group (NDR, $n=61$ ), nonproliferative DR group (NPDR, $n=55$ ), and proliferative DR group (PDR, $n=53$ ). And we also enrolled 94 healthy control participants. We collected demographic, anthropometric, and biochemical data on each subject. LAP and CVAI are calculated according to different formulas for men and women.

Results: Compared with the control group, LAP and CVAI were significantly higher $(\mathrm{P}<0.05)$. After adjusting for confounding factors, LAP (OR: 1.029, 95CI\%: 1.010 1.049, P < 0.05), WC (OR: 1.073, 95CI\%: 1.009-1.141, P < 0.05) and CVAI (OR: 1.017, 95CI\%: $1.000-1.033, \mathrm{P}<0.05)$ were all associated with an increased risk of $\mathrm{DR}$. Furthermore, increased LAP (OR: $1.020,95 \%$ CI: 0.100-0.290) is associated with DR severity $(\mathrm{P}<0.001)$. Moreover, the LAP had the most significant area under the receiver operating characteristics (ROC) curve (AUC) (AUC = 0.728, 95\% CI: 0.653-0.804).

Conclusion: A high LAP is associated with an increased risk of DR in T2DM patients, and the LAP index appears to be a good predictor of DR risk and severity in patients with T2DM, compared with BMI, WC, and CVAI.

Keywords: lipid accumulation product, LAP, Chinese visceral obesity index, CVAI, diabetic retinopathy, DR, abdominal/visceral obesity

\section{Introduction}

Diabetes mellitus (DM) is a chronic disease characterized by hyperglycemia, which can cause a variety of macrovascular and microvascular complications. In 2019, approximately 4.2 million people worldwide died of DM and its complications. ${ }^{1}$ DR is the most common microvascular complication of DM and is also one of the 
causes of blindness in working-age adults. ${ }^{2}$ The prevalence of DM in China ranks the first globally, and DR affects about one-fifth of the patients with diabetes, ${ }^{3}$ which is vital to identify its screening criteria.

About the epidemiological data, the worldwide prevalence of overweight and obesity has reached $33.3 \%$, which has doubled since $1980 .{ }^{4}$ Moreover, obesity, especially abdominal obesity, has been an important risk factor for T2DM. ${ }^{5}$ In addition, studies have shown that abdominal/ visceral obesity is closely related to DR in long-term T2DM patients. ${ }^{6}$ However, the methods to detect abdominal adiposity include dual-energy X-ray absorptiometry (DEXA), computed tomography (CT), magnetic resonance imaging (MRI), and dual bioelectrical impedance analysis (BIA). Also, they are unsuitable for routine clinical practices in a general population because of the radiation exposure, time requirements, and high costs. ${ }^{7}$

This study will propose two new indices-LAP and CVAI. LAP is a new indicator of visceral obesity based on triglycerides and waist circumference. ${ }^{8}$ Studies have shown that LAP index is a powerful factor predicting cardiovascular disease, ${ }^{9,10}$ metabolic syndrome (MetS), ${ }^{11}$ insulin resistance, ${ }^{12}$ and type 2 diabetes. ${ }^{13,14}$ A study of $\mathrm{Wu}$ et $\mathrm{al}^{15}$ has shown that a higher LAP index was associated with a lower risk of DR. But a new study by Wan et al showed that CVAI was not associated with the prevalence of DR. ${ }^{7}$ However, there is still a lack of systematic exploration on the relationship among LAP index, CVAI, and DR in T2DM patients. Therefore, the purpose of our study was to explore the changes of LAP and CVAI levels at different stages of DR and to evaluate the diagnostic efficacy of LAP and CVAI for DR.

\section{Methods}

\section{Subjects, Exclusion Criteria, and Groups}

According to the exclusion criteria, we recruited 169 T2DM patients randomly who were hospitalized in the endocrinology department of the First Affiliated Hospital of Harbin Medical University between May 2019 and December 2020. The diagnosis of T2DM was based on the 1999 World Health Organization standard. ${ }^{16}$

Subjects with the following conditions were excluded: (1) Type 1 diabetes and other types of diabetes; (2) Other eye diseases; (3) Obvious cardiopulmonary insufficiency, in a state of stress (severe trauma, surgery, etc.); (4) Autoimmune diseases, acute and chronic diseases Infected persons; (5) Tumor diseases and blood system diseases; (6) Patients admitted to hospital with the principal diagnosis of diabetic acute complications such as diabetic ketoacidosis, diabetic hyperosmolar coma; (7) Use fibrate lipid-lowering drugs; (8) Participants who refuse to participate in the study and those with incomplete data.

According to the ophthalmic examination, fundus fluorescein angiography (FFA) of professional ophthalmologists and "International Clinical Diabetic Retinopathy Disease Severity Scale", ${ }^{17}$ all T2DM patients were divided into three groups: non-diabetic retinopathy group (NDR, $\mathrm{n}=$ 61), non-proliferative diabetic retinopathy group (NPDR, $\mathrm{n}=55$ ), and proliferative diabetic retinopathy group (PDR, $\mathrm{n}=53$ ). During the same period, 94 healthy people were recruited randomly as the control group in the physical examination center of this hospital. This study was approved by the Ethics Committee of the First Affiliated Hospital of Harbin Medical University and followed the Declaration of Helsinki and STARD guidelines. Written Informed consent was obtained from all participants.

\section{Data Collection}

Collect all subjects' demographic characteristics, history of hypertension, duration of diabetes, diabetes therapy, and complications of diabetes. Researchers took body measurements of height, weight, and waist circumference (WC) of subjects wearing light clothes and no shoes. WC measurement was measured by a uniform soft tape measure $1 \mathrm{~cm}$ above the umbilicus. Measured glycosylated hemoglobin A1c (HbA1c), total cholesterol (TC), triglyceride (TG), high-density lipoprotein (HDL), low-density lipoprotein (LDL), urea nitrogen (BUN), creatinine (Cr) were determined after fasting 8 hours. BMI was calculated as weight $(\mathrm{kg})$ divided by height $\left(\mathrm{m}^{2}\right)$ square. And the $\mathrm{LAP}^{8}$ and $\mathrm{CVAI}^{18}$ were calculated as follows:

Males:

$$
\begin{aligned}
& \mathrm{LAP}=[\mathrm{WC}(\mathrm{cm})-65] \times \mathrm{TG}(\mathrm{mmol} / \mathrm{L}) ; \\
& \mathrm{CVAI}=-267.93+0.68 \times \operatorname{age}(\mathrm{y})+0.03 \times \mathrm{BMI}(\mathrm{kg} / \mathrm{m} 2) \\
& +4.00 \times \mathrm{WC}(\mathrm{cm}) 22.00 \times \log 10 \mathrm{TG}(\mathrm{mmol} / \mathrm{L}) \\
& -16.32 \times \mathrm{HDL}(\mathrm{mmol} / \mathrm{L})
\end{aligned}
$$

Females:

$$
\begin{aligned}
& \mathrm{LAP}=[\mathrm{WC}(\mathrm{cm})-58] \times \mathrm{TG}(\mathrm{mmol} / \mathrm{L}) ; \\
& \mathrm{CVAI}=-187.32+1.71 \times \operatorname{age}(\mathrm{y})+4.32 \times \mathrm{BMI}(\mathrm{kg} / \mathrm{m} 2) \\
& +1.12 \times \mathrm{WC}(\mathrm{cm})+39.76 \times \log 10 \mathrm{TG}(\mathrm{mmol} / \mathrm{L}) \\
& -11.66 \times \mathrm{HDL}(\mathrm{mmol} / \mathrm{L})
\end{aligned}
$$




\section{Definition}

Hypertension was defined as systolic blood pressure (SBP) $\geq 140 \mathrm{mmHg}$, diastolic blood pressure (DBP) $\geq 90 \mathrm{mmHg}$, or a self-reported previous diagnosis of hypertension. Dyslipidemia was defined as TC $\geq 6.22 \mathrm{mmol} /$ $\mathrm{L}(240 \mathrm{mg} / \mathrm{dl}), \mathrm{TG} \geq 2.26 \mathrm{mmol} / \mathrm{L}(200 \mathrm{mg} / \mathrm{dl}), \quad \mathrm{LDL}-\mathrm{L} \geq 4$. $14 \mathrm{mmol} / \mathrm{L}(160 \mathrm{mg} / \mathrm{dl}), \mathrm{HDL}-\mathrm{L}<1.04 \mathrm{mmol} / \mathrm{L}(40 \mathrm{mg} / \mathrm{dl})$.

Participants without DR were defined as having no abnormalities in fundus photographs; participants with NPDR included individuals with intraretinal microaneurysms, hemorrhages, venous beading, prominent microvascular abnormalities. And participants with PDR included individuals with neovascularization or vitreous/preretinal hemorrhages following the Global Diabetic Retinopathy Project Group. ${ }^{17,19}$

\section{Statistical Analysis}

Data analyses were performed with SPSS version 26.0 (IBM Corp., Armonk, NY.).

Continuous variables were expressed as the mean \pm standard deviation (SD) or the median with an interquartile range $(25 \%, 75 \%)$, and categorical variables were presented as percentages (\%). The Kolmogorov-Smirnov (K-S) method of nonparametric testing is used for the data Normality test. And One-way Anova for homogeneity test of data.

One-way analysis of variance was used for the comparison of normally distributed variables between groups, and the LSD test was used for pairwise comparisons within groups; the Kruskal-Wallis $H$-test was used for comparison between non-normally distributed variables between groups, and Kruskal-Wallis single-factor Anova ( $\mathrm{K}$ sample) was used for comparison between groups; Categorical variables were expressed as percentages and compared between groups using the Chi-square test.

The relationships between the LAP index/CVAI and other variables were analyzed by Spearman correlation analysis. Binary logistic regression tests were used to analyze the associations between abdominal obesity indices and DR. And ordered logistic regression tests were used to analyze the associations between abdominal obesity indices and DR severity. The receiver operating characteristics (ROC) curve (AUC) was constructed to evaluate the discrimination of different indices for DR. The maximum Youden index determined the optimal cutoff point. A P-value $<0.05$ (two-sided) was regarded as statistically significant.

\section{Results}

\section{Subject Baseline Characteristics}

The clinical and biochemical characteristics of the subjects are shown in Table 1. The results of the study showed that in each group of T2DM, as the severity of DR increased, the course of the disease was significantly longer, LAP and CVAI were enriched considerably, and the incidence of diabetic peripheral neuropathy (DSPN) and diabetic nephropathy (DN) was higher $(\mathrm{P}<0.05)$.

Compared with the healthy control group, the T2DM groups (NDR, NRPD, and PDR) were older, and they had a significantly higher duration of diabetes, BMI, WC, HbAlc, TG, BUN, LAP, CVAI, and the prevalence of hypertension $(\mathrm{P}<0.05)$. Compared with the NDR group, the duration of diabetes, WC, and CVAI in the DR group (NPDR and PDR) were more extensive, and the PDR group had higher BMI, LAP, TG, TC, and LDL ( $\mathrm{P}<$ $0.05)$. The duration of diabetes, LAP, and the incidence of carotid atherosclerosis in the PDR group were significantly higher than that in the NDR and NPDR groups ( $<$ $0.05)$. The insulin usage rate in the PDR group was higher than that in the NDR group $(\mathrm{P}<0.05)$.

However, there was no significant difference in gender, $\mathrm{HDL}$, and $\mathrm{Cr}$ among the four groups $(\mathrm{P}>0.05)$. In addition, the incidence of hypertension, lower-extremity arterial disease (LEAD), metformin use rate, statin use rates, and $\mathrm{HbA} 1 \mathrm{C}$, age, and BUN were not significantly different in the T2DM groups $(\mathrm{P}>0.05)$ (Table 1).

In addition, the participants were also divided into four groups according to the quartiles of LAP and CVAI (Tables 2 and 3). In the four groups according to the quartiles of LAP (Q1-Q4), there were differences among BMI, WC, HbAlc, TG, LDL, TC, duration of diabetes, and CVAI $(\mathrm{P}<0.05)$. TG is significant among groups for every LAP additional unit $(\mathrm{P}<0.05)$. Moreover, BMI in the Q3-Q4 groups is higher than that in the Q1-Q2 groups $(\mathrm{P}<0.05)$. WC, CVAI, and DR incidence in the $\mathrm{Q} 4$ group are higher than that in other groups.; and the Q4 group had a longer course of disease than Q1 and Q3 $(\mathrm{P}<0.05)$. Compared with the Q1 group, the level of HbA1c, TC, and LDL in Q3-Q4 are higher $(\mathrm{P}<0.05)$, but the prevalence of carotid atherosclerosis in $\mathrm{Q} 3-\mathrm{Q} 4$ is lower $(\mathrm{P}<0.05)$. The majority of DSPN in Q4 is higher than that in Q1, and the bulk of $\mathrm{DN}$ in $\mathrm{O} 3-\mathrm{Q} 4$ is higher than that in $\mathrm{Q} 2(\mathrm{P}<0.05)$ (Table 2).

In the four groups according to the quartiles of CVAI (Q1-Q4), there were differences among age, BMI, WC, 
Table I Clinical and Biochemical Characteristics of the Four Groups of Subjects

\begin{tabular}{|c|c|c|c|c|c|}
\hline Variables & Controls $(n=94)$ & NDR $(n=61)$ & NPDR $(n=55)$ & PDR $(n=53)$ & $\mathbf{P}$ \\
\hline Age (years) & $46(36,54)$ & $55(50,60){ }^{\#}$ & $58(49,63){ }^{\#}$ & $58(50,64){ }^{\#}$ & $<0.05$ \\
\hline Gender (male, \%) & $49(52.1 \%)$ & $29(47.5 \%)$ & $36(65.5 \%)$ & $25(47.2 \%)$ & 0.179 \\
\hline Duration of diabetes (years) & l & $5(0,9) \#$ & $10(5,16) \# \&$ & $15(9.5,22){ }^{\# *}$ & $<0.05$ \\
\hline $\begin{array}{l}\text { Hypertension } \\
\text { (yes, \%) }\end{array}$ & l & $18(29.5 \%)^{\#}$ & $23(41.8 \%)^{\#}$ & $27(50.9 \%)^{\#}$ & $<0.001$ \\
\hline BMI $(\mathrm{kg} / \mathrm{m} 2)$ & $23.44 \pm 3.11$ & $24.94 \pm 3.09^{\#}$ & $25.72 \pm 2.66^{\#}$ & $26.24 \pm 2.75^{\# \&}$ & $<0.05$ \\
\hline$W C(\mathrm{~cm})$ & $83.37 \pm 7.52$ & $87.87 \pm 7.77^{\#}$ & $91.99 \pm 6.79^{\# \&}$ & $93.34 \pm 7.63^{\# \&}$ & $<0.05$ \\
\hline LAP & $27.15(16.40,37.51)$ & $38.16(28.14,62.47)^{\#}$ & $52.02(39.00,78.90))^{\#}$ & $74.06(56.41,122.56)^{\# 8 *}$ & $<0.05$ \\
\hline $\mathrm{HbAlc}(\%)$ & $4.95(4.48,5.60)$ & $8,40(7.05,9.90)^{\#}$ & $8.40(7.00,9.70){ }^{\#}$ & $9.20(8.25,10.35){ }^{\#}$ & $<0.05$ \\
\hline TG (mmol/L) & $1.24(0.90,1.64)$ & $1.59(1.13,2.04)^{\#}$ & $1.80(1.33,2.36)^{\#}$ & $2.32(1.63-3.34) \# \&$ & $<0.05$ \\
\hline $\mathrm{HDL}(\mathrm{mmol} / \mathrm{L})$ & $1.30(I . I I, I .52)$ & $1.20(1.04,1.47)$ & $1.21(1.11,1.36)$ & $1.23(1.03,1.35)$ & $>0.05$ \\
\hline LDL (mmol/L) & $3 . I I(2.60,3.67)$ & $2.79(2.54,3.16)$ & $2.87(2.52,3.24)$ & $3.17(2.76,3.79)^{\&}$ & $<0.05$ \\
\hline $\mathrm{TC}(\mathrm{mmol} / \mathrm{L})$ & $5.08(4.35,5.61)$ & $4.6 I(4.2 I, 5.37)$ & $4.85(4.39,5.82)$ & $5.36(4.63,6.50)^{\&}$ & $<0.05$ \\
\hline BUN (mmol/L) & $4.60(4.04,5.37)$ & $5.36(4.82,6.04)^{\#}$ & $5.77(4.87,7.47)^{\#}$ & $5.92(4.78,7.03)^{\#}$ & $<0.05$ \\
\hline $\mathrm{Cr}(\mathrm{mmol} / \mathrm{L})$ & $63.40(54.85,72.63)$ & $60.80(51.55,67.35)$ & 64.10 (5I.20,7I.80) & $62.00(50.35,71.05)$ & $>0.05$ \\
\hline LEAD (\%) & l & $5 \mathrm{I}(83.6 \%)^{\#}$ & $46(83.6 \%)^{\#}$ & $48(90.6 \%){ }^{\#}$ & $<0.001$ \\
\hline Carotid atherosclerosis (\%) & l & $4 \mathrm{I}(67.2 \%)^{\#}$ & $38(69.1 \%)^{\#}$ & $22(41.5 \%)^{\# z^{*}}$ & $<0.05$ \\
\hline DSPN (\%) & l & $2(3.3 \%)$ & $\mathrm{II}(20.0 \%)^{\# \&}$ & $20(37.7 \%)^{\# \&}$ & $<0.05$ \\
\hline DN (\%) & l & $5(8.2 \%)^{\#}$ & $12(21.8 \%)^{\#}$ & $27(50.9 \%)^{\# \& *}$ & $<0.05$ \\
\hline Statins use (\%) & l & $3 \mathrm{I}(50.8 \%)^{\#}$ & $33(60.0 \%)^{\#}$ & $36(67.9 \%)^{\#}$ & $<0.001$ \\
\hline Insulin use (\%) & I & $43(70.5 \%)^{\#}$ & $46(83.6 \%)^{\#}$ & $50(94.3 \%)^{\# \&}$ & $<0.05$ \\
\hline Metformin use (\%) & l & $42(68.9 \%)^{\#}$ & $43(78.2 \%)^{\#}$ & $31(58.5 \%)^{\#}$ & $<0.001$ \\
\hline CVAl & $78.31 \pm 32.63$ & $108.20 \pm 33.80^{\#}$ & $125.70 \pm 30.60^{\# \&}$ & $133.43 \pm 27.72^{\# \&}$ & $<0.05$ \\
\hline
\end{tabular}

Notes: Compared with healthy control group, ${ }^{*} \mathrm{P}<0.05$; compared with NDR group, ${ }^{\&} \mathrm{p}<0.05$; compared with NPDR group, ${ }^{*} \mathrm{P}<0.05$.

Abbreviations: NDR, non-diabetic retinopathy; NPDR, non-proliferative diabetic retinopathy; PDR, proliferative diabetes retinopathy; BMI, body mass index; LAP, lipid accumulation product; HbAlc, hemoglobin Alc; TG, triglyceride; HDL, high-density lipoprotein; LDL, low-density lipoprotein; TC, total cholesterol; BUN, blood urea nitrogen; Cr, creatinine; LEAD, lower-extremity arterial disease; DSPN, diabetic peripheral neuropathy; DN, diabetic nephropathy; CVAI Chinese visceral adiposity index.

LAP, TG, HDL, BUN, Cr, and duration of diabetes $(\mathrm{P}<$ 0.05). WC is significant among groups for every CVAI additional unit $(\mathrm{P}<0.05)$. Moreover, the $\mathrm{Q} 3-\mathrm{Q} 4$ groups are older than that in $\mathrm{Q} 1-\mathrm{Q} 2$ groups $(\mathrm{P}<0.05)$, and $\mathrm{BMI}$ in $\mathrm{Q} 4$ is higher than that in the other groups $(\mathrm{P}<0.05)$. LAP and TG in Q2-Q4 are more elevated compared with the Q1 group ( $\mathrm{P}<0.05)$. HDL level in the $\mathrm{Q} 3-\mathrm{Q} 4$ group is lower than in Q1; however, $\mathrm{Cr}$ in Q3-Q4 and BUN in Q4 is higher than in $\mathrm{Q} 1(\mathrm{P}<0.05)$. In addition, the incidence of $\mathrm{DR}$ in Q4 and Q2 is higher than that in Q1; the incidence of $\mathrm{DN}$ in $\mathrm{Q} 4$ is higher than that in $\mathrm{Q} 1-\mathrm{Q} 2(\mathrm{P}<0.05)$ (Table 3).

\section{Associations Among LAP, CVAI, and Other Variables}

Tables 4 and 5 show that the relationship between LAP, CVAI and the other variables, respectively. In Table 4 , age $(r=0.275$, $\mathrm{P}<0.001)$, duration of diabetes $(\mathrm{r}=0.539, \mathrm{P}<0.001)$, HbA1C $(\mathrm{r}=0.558, \mathrm{P}<0.001), \mathrm{TG}(\mathrm{r}=0.912, \mathrm{P}<0.001), \mathrm{TC}(\mathrm{r}=0.238$, $\mathrm{P}<0.001)$, LDL $(\mathrm{r}=0.188, \mathrm{P}=0.002)$, and BUN $(\mathrm{r}=0.309$,
$\mathrm{P}<0.001)$ are significantly positively associated with LAP, while HDL $(\mathrm{r}=-0.309, \mathrm{P}<0.001)$ is significantly negatively correlated with LAP. However, there was no significant correlation between $\mathrm{Cr}$ and LAP (P $>0.05)$ (Table 4).

In Table 5, age $(\mathrm{r}=0.475, \mathrm{P}<0.001)$, duration of diabetes $(\mathrm{r}=0.581, \mathrm{P}<0.001), \mathrm{HbA1C}(\mathrm{r}=0.504, \mathrm{P}<0.001), \mathrm{TG}$ $(\mathrm{r}=0.575, \mathrm{P}<0.001)$, BUN $(\mathrm{r}=0.389, \mathrm{P}<0.001)$ and $\mathrm{Cr}$ $(\mathrm{r}=0.197, \mathrm{P}=0.001)$ are significantly positively associated with CVAI, while HDL $(\mathrm{r}=-0.399, \mathrm{P}<0.001)$ is significantly negatively correlated with CVAI. However, there was no significant correlation among TC, LDL and CVAI $(\mathrm{P}>0.05)$ (Table 5).

\section{Association Among LAP, WC, CVAI, and DR Severity}

As shown in Table 6, binary logistic regression analysis showed that a unit increase in LAP (OR $=1.033$, $95 \% \mathrm{CI}=1.018-1.048), \mathrm{WC}(\mathrm{OR}=1.093,95 \% \mathrm{CI}=$ $1.042-1.147)$, and CVAI $(\mathrm{OR}=1.023,95 \% \mathrm{CI}=$ 1.011-1.034) was significantly associated with the 
Table 2 General Characteristics of Patients Divided by Quartiles of LAP

\begin{tabular}{|c|c|c|c|c|c|}
\hline Variables & QI $(n=42)$ & Q2 $(n=42)$ & Q3 $(n=42)$ & Q4 $(n=43)$ & $\mathbf{P}$ \\
\hline Age (years) & $55.52 \pm 8.75$ & $58.93 \pm 8.70$ & $54.67 \pm 9.91$ & $55.33 \pm 9.23$ & 0.143 \\
\hline Gender (male, \%) & $25(59.2 \%)$ & $22(52.4 \%)$ & $19(45.2 \%)$ & $24(55.8 \%)$ & 0.599 \\
\hline Duration of diabetes (years) & $6(1.75,11.25)$ & $10(2.5,17)$ & $7.5(3.75,17)$ & $13(9,20) \#^{* *}$ & $<0.05$ \\
\hline $\begin{array}{l}\text { Hypertension } \\
\text { (yes, \%) }\end{array}$ & $15(35.7 \%)$ & $16(38.1 \%)$ & $17(40.5 \%)$ & $20(46.5 \%)$ & 0.767 \\
\hline BMI $\left(\mathrm{kg} / \mathrm{m}^{2}\right)$ & $23.44 \pm 2.27$ & $25.20 \pm 2.57^{\#}$ & $26.38 \pm 2.20^{\# \&}$ & $27.34 \pm 2.92^{\# \&}$ & $<0.001$ \\
\hline WC $(\mathrm{cm})$ & $84.43 \pm 6.85$ & $90.93 \pm 6.25^{\#}$ & $92.66 \pm 5.5 I^{\#}$ & $95.6 \mathrm{I} \pm 7.67^{\# \alpha^{*}}$ & $<0.001$ \\
\hline LAP & $26.26(21.48,32.14)$ & $46.41(40.2,51.23){ }^{\#}$ & $66.08(62.58,74.62){ }^{\# \&}$ & 96.14 (88.1I,150.92) $\# \&^{*}$ & $<0.05$ \\
\hline HbAlc (\%) & $8.25 \pm 2.05$ & $8.64 \pm 1.75$ & $9.15 \pm 2.19^{\#}$ & $9.38 \pm 1.91{ }^{\#}$ & $<0.05$ \\
\hline $\mathrm{TG}(\mathrm{mmol} / \mathrm{L})$ & $1.16(0.9,1.31)$ & $1.52(1.36,1.83)^{\#}$ & $2.14(1.87,2.35) \# \&$ & $3.21(2.53,4.60){ }^{\# 2^{*}}$ & $<0.05$ \\
\hline $\mathrm{HDL}(\mathrm{mmol} / \mathrm{L})$ & $1.27(1.09,1.50)$ & $1.24(1.11,1.38)$ & $1.15(1.02,1.29)$ & $1.23(1.04,1.36)$ & $>0.05$ \\
\hline LDL (mmol/L) & $2.69(2.48,3.04)$ & $2.83(2.64,3.21)$ & $3.29(2.62,3.95){ }^{\#}$ & $3.05(2.73,3.54){ }^{\#}$ & $<0.05$ \\
\hline $\mathrm{TC}(\mathrm{mmol} / \mathrm{L})$ & $4.5 \mathrm{I}(4.07,5.09)$ & $4.78(4.47,5.25)$ & $5.44(4.49,6.49) \#$ & $5.26(4.72,6.54){ }^{\# \&}$ & $<0.05$ \\
\hline BUN (mmol/L) & $5.28(4.56,6.22)$ & $5.87(4.90,6.95)$ & $5.69(4.63,6.87)$ & $5.82(4.9,7.37)$ & $>0.05$ \\
\hline $\mathrm{Cr}(\mathrm{mmol} / \mathrm{L})$ & $61.25(48.28,67.38)$ & $63.7(54.43,7 \mid .43)$ & $59.15(46.63,77.3)$ & $62.3(52.1,70.5)$ & $>0.05$ \\
\hline LEAD (\%) & $34(81.0 \%)$ & $39(92.9 \%)$ & $34(81.0 \%)$ & $38(88.4 \%)$ & 0.312 \\
\hline Carotid atherosclerosis (\%) & $32(76.2 \%)$ & $30(7 \mid .4 \%)$ & $20(47.6 \%)^{\#}$ & $19(44.2 \%)^{\#}$ & $<0.05$ \\
\hline DSPN (\%) & $3(7.1 \%)$ & $6(14.3 \%)$ & $\mathrm{II}(26.2 \%)$ & $13(30.2 \%){ }^{\#}$ & $<0.05$ \\
\hline DN (\%) & $6(14.3 \%)$ & $5(11.9 \%)$ & $16(38.1 \%)^{\&}$ & $17(39.5 \%)^{\&}$ & $<0.05$ \\
\hline Statins use (\%) & $18(42.9 \%)$ & $24(57.1 \%)$ & $29(69.0 \%)$ & $29(67.4 \%)$ & 0.055 \\
\hline Insulin use (\%) & $30(71.4 \%)$ & $34(81.0 \%)$ & $36(85.7 \%)$ & $39(90.7 \%)$ & 0.118 \\
\hline Metformin use (\%) & $24(57.1 \%)$ & $29(69.0 \%)$ & $29(69.0 \%)$ & $34(79.1 \%)$ & 0.190 \\
\hline CVAl & $89.46 \pm 29.09$ & $123.24 \pm\left. 25.0\right|^{\#}$ & $128.11 \pm 20.52^{\#}$ & $|45.84 \pm 26.8|^{\# \&^{*}}$ & $<0.001$ \\
\hline DR (\%) & $16(38.1 \%)$ & $28(64.3 \%)$ & $26(61.9 \%)$ & $39(90.7 \%){ }^{\# *}$ & $<0.001$ \\
\hline
\end{tabular}

Notes: Compared with healthy control group, ${ }^{\#} \mathrm{P}<0.05$; compared with NDR group, ${ }^{\&} \mathrm{P}<0.05$; compared with NPDR group, ${ }^{*} \mathrm{P}<0.05$.

Abbreviations: NDR, non-diabetic retinopathy; NPDR, non-proliferative diabetic retinopathy; PDR, proliferative diabetes retinopathy; BMI, body mass index; LAP, lipid accumulation product; HbAlc, hemoglobin Alc; TG, triglyceride; HDL, high-density lipoprotein; LDL, low-density lipoprotein; TC, total cholesterol; BUN, blood urea nitrogen; Cr, creatinine; LEAD, lower-extremity arterial disease; DSPN, diabetic peripheral neuropathy; DN, diabetic nephropathy; CVAI Chinese visceral adiposity index.

prevalence of DR $(\mathrm{P}<0.05)$. After adjusting for age, gender, duration of diabetes, HbA1C, HDL, LDL, TC, statins use, insulin use, metformin use and hypertension, LAP $(\mathrm{OR}=1.029,95 \% \mathrm{CI}=1.010-1.049)$, WC $(\mathrm{OR}=1.073,95 \% \mathrm{CI}=1.009-1.141)$ and $\mathrm{CVAI}$ $(\mathrm{OR}=1.017,95 \% \mathrm{CI}=1.000-1.033)$ were still associated with an increased risk of DR $(\mathrm{P}<0.05)$. Therefore, LAP, WC, and CVAI may be independent risk factors for DR (Table 6).

Moreover, in Table 7, ordered logistic regression analysis showed that only increased LAP (OR $=1.020,95 \%$ $\mathrm{CI}=0.100-0.290, \mathrm{P}<0.001)$ is associated with DR severity. However, as LAP increased, the severity of DR was significantly higher. And the results were consistent with the four groups according to the quartiles of LAP (Q1-Q4), in which DR incidence in the Q4 group is higher than that in other groups (Table 7).

\section{Receiver-Operating Characteristics (ROC) Curve Analysis}

We found that the ROC curve analyzed the diagnostic ability of abdominal obesity indices, including WC, LAP, and CVAI for DR. The differences between the area under the curve of WC, LAP, and CVAI were all significant $(\mathrm{P}<0.05)$ (Figure 1). Area under ROC curve of LAP, WC, and CVAI for DR was 0.728 (95\% CI: $0.653-0.804), 0.664$ (95\% CI: $0.580-0.749)$, and 0.677 (95\% CI: $0.593-0.761)$, respectively (all $\mathrm{P}<0.001$ ). LAP had the largest area under the ROC curve compared to the other indices, and the cut-off with the biggest Youden index of LAP was 37.56 with a sensitivity of $84.3 \%$ and a specificity of $49.2 \%$.

\section{Discussion}

Obesity has been confirmed to be related to various metabolic diseases, such as hypertension, diabetes, 
Table 3 General Characteristics of Patients Divided by Quartiles of CVAI

\begin{tabular}{|c|c|c|c|c|c|}
\hline Variables & QI $(n=42)$ & Q2 (n = 43) & Q3 (n = 4I) & Q4 (n = 43) & $\mathbf{P}$ \\
\hline Age (years) & $51.76 \pm 8.72$ & $54.30 \pm 8.41$ & $58.76 \pm 8.96^{\# \&}$ & $59.63 \pm 8.80^{\# 8}$ & $<0.001$ \\
\hline Gender (male, \%) & $17(40.5 \%)$ & $21(48.8 \%)$ & $23(56.1 \%)$ & $29(67.4 \%)$ & 0.082 \\
\hline Duration of diabetes (years) & $5(0,10)$ & $10(5,17){ }^{\#}$ & $8(4.5,17)$ & $14(8,20) \#$ & $<0.05$ \\
\hline $\begin{array}{l}\text { Hypertension } \\
\text { (yes, \%) }\end{array}$ & $10(23.8 \%)$ & $20(46.5 \%)$ & $16(39.0 \%)$ & $22(51.2 \%)$ & 0.056 \\
\hline BMI $\left(\mathrm{kg} / \mathrm{m}^{2}\right)$ & $23.23 \pm 2.28$ & $25.37 \pm 1.93^{\#}$ & $25.54 \pm 2.06^{\#}$ & $28.21 \pm 2.80^{\# 8^{*}}$ & $<0.001$ \\
\hline$W C(\mathrm{~cm})$ & $82.69 \pm 5.74$ & $88.59 \pm 3.51^{\#}$ & $93.02 \pm 4.62^{\# \&}$ & $99.33 \pm 5.02^{\# 8^{*}}$ & $<0.001$ \\
\hline LAP & $28.74(21.78,38.97)$ & $53.25(39.0,70.5){ }^{\#}$ & $66.08(47.33,86.95){ }^{\#}$ & $78.21(53.63,105.93){ }^{\# \&}$ & $<0.05$ \\
\hline HbAlc (\%) & $8.64 \pm 2.16$ & $8.90 \pm 1.94$ & $9.00 \pm 2.25$ & $8.87 \pm 1.72$ & 0.843 \\
\hline TG $(\mathrm{mmol} / \mathrm{L})$ & $1.26(1.00,1.82)$ & $2.01(1.40,2.52){ }^{\#}$ & $2.02(1.58,2.62){ }^{\#}$ & $2.08(1.48,2.87){ }^{\#}$ & $<0.05$ \\
\hline $\mathrm{HDL}(\mathrm{mmol} / \mathrm{L})$ & $1.32(1.19,1.68)$ & $1.17(1.05,1.38)$ & $1.21(1.01,1.34)^{\#}$ & $1.15(0.99,1.35)^{\#}$ & $<0.05$ \\
\hline $\mathrm{LDL}(\mathrm{mmol} / \mathrm{L})$ & $2.88(2.60,3.66)$ & $2.80(2.52,3.38)$ & $2.97(2.55,3.56)$ & $2.93(2.72,3.25)$ & $>0.05$ \\
\hline $\mathrm{TC}(\mathrm{mmol} / \mathrm{L})$ & $4.94(4.31,6.15)$ & $4.87(4.26,5.89)$ & $4.83(4.34,6.35)$ & $4.85(4.52,5.49)$ & $>0.05$ \\
\hline BUN (mmol/L) & $4.98(4.54,5.78)$ & $5.59(4.86,6.67)$ & $5.77(4.59,7.30)$ & $6.14(5.00,7.48))^{\#}$ & $<0.05$ \\
\hline $\mathrm{Cr}(\mathrm{mmol} / \mathrm{L})$ & $52.45(45.60,65.93)$ & $61.00(50.00,69.10)$ & $69.50(54.05,76.95){ }^{\#}$ & $66.30(5.80,71.80){ }^{\#}$ & $<0.05$ \\
\hline LEAD (\%) & $32(76.2 \%)$ & $36(83.7 \%)$ & $37(90.2 \%)$ & $40(93.0 \%)$ & 0.120 \\
\hline Carotid atherosclerosis (\%) & $28(66.7 \%)$ & $22(51.2 \%)$ & $27(65.9 \%)$ & $24(55.8 \%)$ & 0.382 \\
\hline DSPN (\%) & $6(14.3 \%)$ & $5(11.6 \%)$ & $9(22.0 \%)$ & $13(30.2 \%)$ & 0.125 \\
\hline DN (\%) & $5(11.9 \%)$ & $7(16.3 \%)$ & $12(29.3 \%)$ & $20(46.5 \%) \# \&$ & $<0.05$ \\
\hline Statins use (\%) & $20(47.6 \%)$ & $29(67.4 \%)$ & $26(63.4 \%)$ & $25(58.1 \%)$ & 0.277 \\
\hline Insulin use (\%) & $29(69.0 \%)$ & $38(88.4 \%)$ & $34(82.9 \%)$ & $38(88.4 \%)$ & 0.065 \\
\hline Metformin use (\%) & $25(59.5 \%)$ & $28(65.1 \%)$ & $26(63.4 \%)$ & $37(86.0 \%))^{\#}$ & $<0.05$ \\
\hline CVAI & $80.63 \pm 21.92$ & $112.24 \pm 6.65^{\#}$ & $132.95 \pm 5.72^{\# \&}$ & $106.97 \pm 14.86^{\# *}$ & $<0.001$ \\
\hline DR (\%) & $16(38.1 \%)$ & $30(69.8 \%) \#$ & $27(65.9 \%)$ & $35(81.4 \%)^{\#}$ & $<0.001$ \\
\hline
\end{tabular}

Notes: Compared with healthy control group, ${ }^{*} \mathrm{P}<0.05$; compared with NDR group, ${ }^{\&} \mathrm{P}<0.05$; compared with NPDR group, *P<0.05;

Abbreviations: NDR, non-diabetic retinopathy; NPDR, non-proliferative diabetic retinopathy; PDR, proliferative diabetes retinopathy; BMI, body mass index; LAP, lipid accumulation product; HbAlc, hemoglobin Alc; TG, triglyceride; HDL, high-density lipoprotein; LDL, low-density lipoprotein; TC, total cholesterol; BUN, blood urea nitrogen; Cr, creatinine; LEAD, lower-extremity arterial disease; DSPN, diabetic peripheral neuropathy; DN, diabetic nephropathy; CVAI Chinese visceral adiposity index.

Table 4 Associations Between LAP and Other Variables

\begin{tabular}{|l|c|c|}
\hline Variables & $\mathbf{r}$ & $\mathbf{P}$ \\
\hline Age (years) & 0.275 & $<0.00 \mathrm{I}$ \\
HbAIc (\%) & 0.558 & $<0.00 \mathrm{I}$ \\
Duration of diabetes (years) & 0.539 & $<0.00 \mathrm{I}$ \\
TC & 0.238 & $<0.00 \mathrm{I}$ \\
TG & 0.912 & $<0.00 \mathrm{I}$ \\
HDL & -0.309 & $<0.00 \mathrm{I}$ \\
LDL & 0.188 & 0.002 \\
BUN & 0.309 & $<0.00 \mathrm{I}$ \\
Cr & 0.039 & 0.527 \\
\hline
\end{tabular}

Abbreviations: HbAlc, hemoglobin Alc; HDL, high density lipoprotein; LDL, low density lipoprotein; TC, total cholesterol; BUN, blood urea nitrogen; $\mathrm{Cr}$, creatinine.
Table 5 Associations Between CVAI and Other Variables

\begin{tabular}{|l|c|c|}
\hline Variables & $\mathbf{r}$ & $\mathbf{P}$ \\
\hline Age (years) & 0.475 & $<0.00 \mathrm{I}$ \\
HbAlc (\%) & 0.504 & $<0.00 \mathrm{I}$ \\
Duration of diabetes (years) & $0.58 \mathrm{I}$ & $<0.00 \mathrm{I}$ \\
TC & -0.003 & 0.960 \\
TG & 0.575 & $<0.00 \mathrm{I}$ \\
HDL & -0.399 & $<0.00 \mathrm{I}$ \\
LDL & -0.009 & 0.884 \\
BUN & 0.389 & $<0.00 \mathrm{I}$ \\
Cr & 0.197 & $0.00 \mathrm{I}$ \\
\hline
\end{tabular}

Abbreviations: $\mathrm{HbAlc}$, hemoglobin Alc; HDL, high density lipoprotein; LDL, low density lipoprotein; TC, total cholesterol; BUN, blood urea nitrogen; Cr, creatinine. abnormal lipid metabolism, and cardiovascular diseases. Up to now, visceral obesity has been proven to be a more critical risk factor for T2DM. ${ }^{13,14}$ In a multiethnic crosssectional study, Angela et al found that visceral obesity was significantly positively correlated with DR. Effective processing of visceral fat can improve the body's susceptibility to DR. ${ }^{20}$ The study has shown that visceral adipose tissue has a more substantial effect on insulin resistance than subcutaneous adipose tissue, ${ }^{21}$ and insulin resistance is closely related to $\mathrm{DR},{ }^{22}$ so visceral fat may affect DR through insulin resistance. Moreover, compared with subcutaneous adipose tissue, visceral adipose tissue has more vital metabolic activity and higher lipolysis, secreting more lipid-derived 
Table 6 Association Among LAP, WC, CVAI and DR

\begin{tabular}{|l|c|c|c|c|c|c|}
\hline & & LAP & & WC & CVAI \\
\cline { 2 - 7 } & $\mathbf{P}$ & OR (95\% Cl) & $\mathbf{P}$ & OR (95\% Cl) & P & OR (95\% CI) \\
\hline Model 1 & $<0.001$ & $1.033(1.018-1.048)$ & $<0.001$ & $1.093(1.042-1.147)$ & $<0.001$ & $1.023(1.011-1.034)$ \\
Model 2 & $<0.001$ & $1.031(1.014-1.048)$ & 0.016 & $1.071(1.013-1.133)$ & 0.012 & $1.018(1.004-1.032)$ \\
Model 3 & 0.003 & $1.030(1.010-1.050)$ & 0.016 & $1.077(1.014-1.144)$ & 0.031 & $1.018(1.002-1.034)$ \\
Model 4 & 0.003 & $1.029(1.010-1.049)$ & 0.024 & $1.073(1.009-1.141)$ & 0.049 & $1.017(1.000-1.033)$ \\
\hline
\end{tabular}

Notes: Model I: Crude model; Model 2: Model I+adjust for age, gender, duration of diabetes; Model 3: Model 2+ adjust for HbAIc, HDL, LDL, TC; Model 4: Model 3+ adjust for hypertension, statins use, insulin use and metformin use.

Table 7 Association Among LAP, WC, CVAI and DR Severity

\begin{tabular}{|l|c|r|}
\hline Variables & OR (95\% Cl) & P \\
\hline LAP & $1.020(0.100-0.290)$ & $<0.001$ \\
WC & $1.059(-0.035-0.149)$ & 0.226 \\
CVAI & $1.002(-0.02-0.025)$ & 0.829 \\
\hline
\end{tabular}

Abbreviations: LAP, lipid accumulation product; CVAI Chinese visceral adiposity index.

cytokines and inflammatory cytokines. ${ }^{23}$ Lipid-derived cytokines can aggravate insulin resistance, and inflammatory factors can cause endothelial dysfunction. Inflammatory factors and endothelial dysfunction are related to the occurrence of DR. ${ }^{24}$ Therefore, the effect of visceral fat on DR may be more significant.

However, the correlation between visceral obesity and diabetes complications is limited. A meta-analysis in 2018 reported that obesity (assessed by BMI) significantly increased the risk of DR; this effect mainly referred to nonproliferative DR and patients with T2DM. ${ }^{25}$ Also, a crosssectional study showed that abdominal obesity (assessed by WC) also correlated with $\mathrm{DR} \cdot{ }^{26}$ In addition to the traditional indicators, there are many new indicators of abdominal obesity, but which is more representative is unknown. Nevertheless, many previous studies have confirmed the correlation between traditional obesity evaluation indicators BMI, WC, and DR. In our research, we propose two new hands of obesity - LAP and CVAI. LAP, a newly developed biomarker of central lipid accumulation, is estimated based on a combination of WC and TG levels. ${ }^{15}$ CVAI is a novel visceral adiposity index designed in Chinese adults associated with visceral fat and insulin resistance. ${ }^{18,27}$ Our study found WC, LAP, and CVAI were significantly associated with a greater prevalence of DR.

Based on the binary logistic regression analysis, we found that LAP and CVAI were all significantly correlated with the prevalence of DR. However, ordered logistic regression analysis showed that higher LAP was associated with increased severity of DR. LAP was an independent risk factor for DR, which the difference was still significant after adjusting for confounding factors. Further ROC curve results showed that the diagnostic accuracy of LAP in DR was higher than that of other indices. Compared with imaging examination, LAP is easier to obtain and use and less expensive. Therefore, LAP may be a better indicator for screening DR in patients with T2DM. However, these findings contradict those of the current study, in which they found that a higher LAP index was associated with a lower risk of DR. ${ }^{15}$ Due to a lesser capacity for insulin secretion, people with a long-term duration of diabetes tend to have a lower LAP than those with shorter diabetes duration. Therefore, it could be a critical factor in explaining the inverse association of the LAP index and DR. ${ }^{15}$

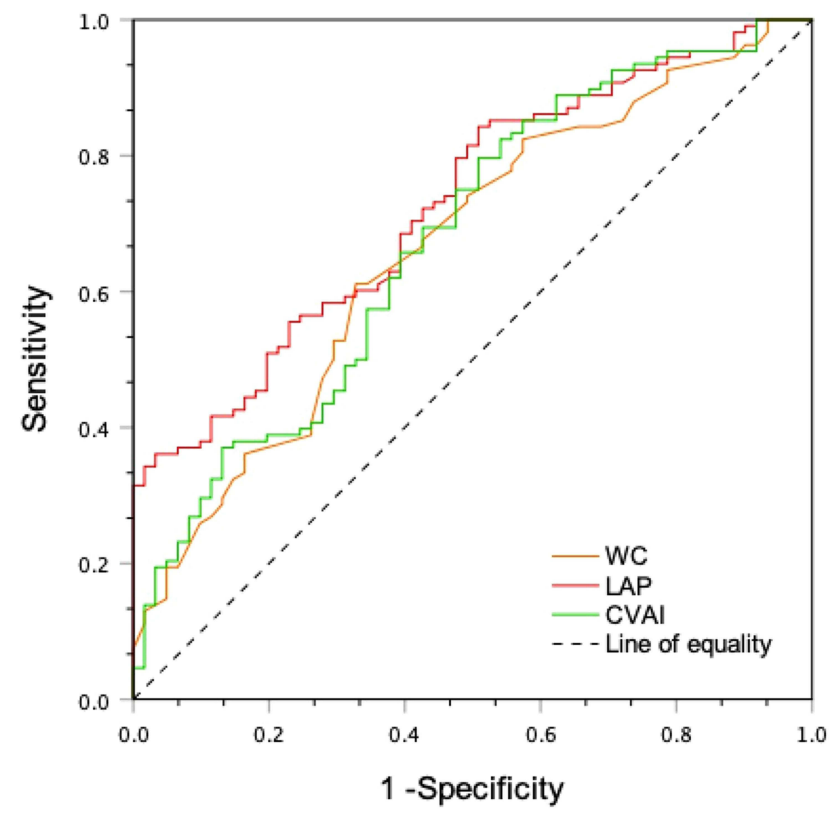

Figure I The ROC curve of abdominal obesity indices for diagnosing. Abbreviations: WC, waist circumference; LAP, Lipid accumulation product; CVAI, Chinese visceral adiposity index. 
Meanwhile, different results may be caused by other study designs. Wu et al included 427 T2DM subjects in their study, of which 68 were in the NPDR group, and only 8 were in the PDR group. In the study by Wan et al. Among the 4658 diabetic subjects, only 544 had DR, and DR has not to stage. The proportion of DR in the above two items was small, leading to different study results. The current research results on the relationship between LAP and DR are different, and DR is affected by many factors. Therefore, a larger sample size of research is needed in the future to clarify the relationship between the LAP index and DR and its severity.

In addition, previous reports suggested LAP index is a better determinant of cardiometabolic risk than anthropometric measures (ie, BMI and WC). ${ }^{28}$ Excess adipose tissue can be harmful in the context of DM development through a relationship between obesity and metabolic disorders associated with chronic inflammation. ${ }^{29}$ The studies have found that individuals with DM or pre-diabetes have higher levels of inflammatory markers, such as TNF- $\alpha$, IL6, and C-reactive protein (CRP) ${ }^{30,31}$ They all play an essential role in the development and progression of DM and are highly involved in the atherogenic process. ${ }^{32,33}$ As we all know, chronic inflammation and oxidative stress are involved in the development of DR. Recent studies have shown the relationship between LAP, oxidative stress, ${ }^{34}$ and inflammation. ${ }^{35}$ In conclusion, LAP may be closely related to chronic inflammation, cardiovascular diseases, diabetes, and complications.

To the best of our knowledge, this study is the first to study the relationship among LAP, CVAI, and DR in groups based on the DR stage and compare the diagnostic efficacy of different obesity indicators for DR. However, this study also has several limitations that should be noted. Firstly, this was a cross-sectional study. Therefore, we could only examine the correlation between LAP and DR; causal inferences cannot be made. Second, the sample size was small, and patient selection bias might exist. Finally, other potential confounders were not included, such as exercise and diet habits.

\section{Conclusion}

In conclusion, the LAP index is an independent risk factor for DR in T2DM patients, which the more severe the stage of DR, the higher the LAP level was. Compared with WC and CVAI, the LAP index is more powerful. As obesity and DR are complex and multi-factorial traits influenced by multiple factors, future longitudinal studies with larger sample sizes are needed to explore this association.

\section{Acknowledgments}

This work was supported by a grant from the Fund of Scientific Research Innovation of the First Affiliated Hospital of Harbin Medical University [grant number 2020M27, China].

\section{Disclosure}

The authors report no conflicts of interest in this work.

\section{References}

1. Saeedi P, Salpea P, Karuranga S, et al. Mortality attributable to diabetes in 20-79 years old adults, 2019 estimates: results from the International Diabetes Federation Diabetes Atlas, 9 edition. Diabetes Res Clin Pract. 2020;162:108086. doi:10.1016/j.diabres.2020.108086

2. Lin S, Gupta B, James N, et al. Visual impairment certification due to diabetic retinopathy in North and Eastern Devon. Acta Ophthalmol. 2017;95(8):e756-e762. doi:10.1111/aos.13400

3. Song P, Yu J, Chan KY, et al. prevalence, risk factors and burden of diabetic retinopathy in China: a systematic review and meta-analysis. J Glob Health. 2018;8(1):010803. doi:10.7189/jogh.08.010803

4. Chooi Y, Ding C, Magkos F. The epidemiology of obesity. Metabolism. 2019;92:6-10. doi:10.1016/j.metabol.2018.09.005

5. Defronzo R. Banting Lecture. From the triumvirate to the ominous octet: a new paradigm for the treatment of type 2 diabetes mellitus. Diabetes. 2009;58(4):773-795. doi:10.2337/db09-9028

6. Moh A, Neelam K, Zhang X, et al. Excess visceral adiposity is associated with diabetic retinopathy in a multiethnic Asian cohort with longstanding type 2 diabetes. Endocr Res. 2018;43(3):186-194. doi:10.1080/07435800.2018.1451541

7. Wan H, Wang Y, Xiang Q, et al. Associations between abdominal obesity indices and diabetic complications: Chinese visceral adiposity index and neck circumference. Cardiovasc Diabetol. 2020;19(1):118. doi:10.1186/s12933-020-01095-4

8. Kahn H. The "lipid accumulation product" performs better than the body mass index for recognizing cardiovascular risk: a populationbased comparison. BMC Cardiovasc Disord. 2005;5:26. doi:10.1186/ 1471-2261-5-26

9. Kyrou I, Panagiotakos DB, Kouli G-M, et al. Lipid accumulation product in relation to 10 -year cardiovascular disease incidence in Caucasian adults: the ATTICA study. Atherosclerosis. 2018;279:10-16. doi:10.1016/j.atherosclerosis.2018.10.015

10. Vieira J, Braz MAD, Gomes FO, et al. Cardiovascular risk assessment using the lipid accumulation product index among primary healthcare users: a cross-sectional study. Sao Paulo Medical Journal = Revista Paulista de Medicina. 2019;137(2):126-131. doi:10.1590/1516-3180.2018.0293240119

11. Gu Z, Zhu P, Wang Q, et al. obesity and lipid-related parameters for predicting metabolic syndrome in Chinese elderly population. Lipids Health Dis. 2018;17(1):289. doi:10.1186/s12944-018-0927-x

12. Xia C, Li R, Zhang S, et al. Lipid accumulation product is a powerful index for recognizing insulin resistance in non-diabetic individuals. Eur J Clin Nutr. 2012;66(9):1035-1038. doi:10.1038/ejen.2012.83

13. Yan G, Li F, Elia C, et al. association of lipid accumulation product trajectories with 5 -year incidence of type 2 diabetes in Chinese adults: a cohort study. Nutr Metab. 2019;16:72. doi:10.1186/ s12986-019-0399-7

14. Nusrianto R, Ayundini G, Kristanti M, et al. Visceral adiposity index and lipid accumulation product as a predictor of type 2 diabetes mellitus: the Bogor cohort study of non-communicable diseases risk factors. Diabetes Res Clin Pract. 2019;155:107798. doi:10.1016/j. diabres.2019.107798 
15. Wu J, Zhong Y, Yue S, et al. association between lipid accumulation product and diabetic retinopathy based on a community-based survey in Chinese with type 2 diabetes. Diabetes Metabol Syndr Obesity. 2019;12:513-518. doi:10.2147/DMSO.S195578

16. Alberti K, Zimmet P. Definition, diagnosis and classification of diabetes mellitus and its complications. Part 1: diagnosis and classification of diabetes mellitus provisional report of a WHO consultation. Diabetic Med. 1998;15(7):539-553. doi:10.1002/ (SICI)1096-9136(199807)15:7<539::AID-DIA668>3.0.CO;2-S

17. Wilkinson C, Ferris FL, Klein RE, et al. Proposed international clinical diabetic retinopathy and diabetic macular edema disease severity scales. Ophthalmology. 2003;110(9):1677-1682. doi:10.1016/S0161-6420(03)00475-5

18. Xia M, Chen Y, Lin H-D, et al. A indicator of visceral adipose dysfunction to evaluate metabolic health in adult Chinese. Sci Rep. 2016;6:38214. doi:10.1038/srep38214

19. Xin L, Yu ZW, Yang CW, et al. Association among abdominal obesity induces, diabetic retinopathy and metabolic syndrome in community: a cross-sectional study. Endocrinol Metabol. 2021;5(4):169.

20. Angela M, Neelam K, Zhang X, et al. Excess visceral adiposity is associated with diabetic retinopathy in a multiethnic Asian cohort with longstanding type 2 diabetes. Endocr Res. 2018;43(3):186-194.

21. Liu L, Feng J, Zhang G, et al. Visceral adipose tissue is more strongly associated with insulin resistance than subcutaneous adipose tissue in Chinese subjects with pre-diabetes. Curr Med Res Opin. 2018;34 (1):123-129. doi:10.1080/03007995.2017.1364226

22. Anan F, Masaki T, Ito Y, et al. Diabetic retinopathy is associated with visceral fat accumulation in Japanese type 2 diabetes mellitus patients. Metabolism. 2010;59(3):314-319. doi:10.1016/j.metabol.2009.06.001

23. Ibrahim M. Subcutaneous and visceral adipose tissue: structural and functional differences. Obesity Revi. 2010;11(1):11-18. doi:10.1111/ j.1467-789X.2009.00623.x

24. Martina T, Vrabec R, Vidas Pauk S, Bulum T, Ljubić S. Systemic inflammation and dyslipidemia are associated with retinopathy in type 2 but not in type 1 diabetes. Scand J Clin Lab Invest. 2020;80:6.

25. Zhu W, Wu Y, Meng Y-F, et al. association of obesity and risk of diabetic retinopathy in diabetes patients: a meta-analysis of prospective cohort studies. Medicine. 2018;97(32):e11807. doi:10.1097/ MD.0000000000011807

26. Raman R, Rani PK, Gnanamoorthy P, et al. Association of obesity with diabetic retinopathy: Sankara Nethralaya Diabetic Retinopathy Epidemiology and Molecular Genetics Study (SN-DREAMS Report no. 8). Acta Diabetol. 2010;47(3):209-215. doi:10.1007/s00592-009-0113-8
27. Xia M, Lin H-D, Chen L-Y, et al. Association of visceral adiposity and its longitudinal increase with the risk of diabetes in Chinese adults: a prospective cohort study. Diabetes Metab Res Rev. 2018;34(7):e3048. doi:10.1002/dmrr.3048

28. Biyik Z, Guney I. Lipid accumulation product and visceral adiposity index: two new indices to predict metabolic syndrome in chronic kidney disease. Eur Rev Med Pharmacol Sci. 2019;23(5):2167-2173. doi:10.26355/eurrev 201903 17262

29. Hamada D, Maynard R, Schott E, et al. Suppressive effects of insulin on tumor necrosis factor-dependent early osteoarthritic changes associated with obesity and Type 2 diabetes mellitus. Arth Rheumatol. 2016;68(6):1392-1402. doi:10.1002/art.39561

30. Rodrigues K, Pietrani NT, Bosco AA, et al. IL-6, TNF- $\alpha$, and IL-10 levels/polymorphisms and their association with type 2 diabetes mellitus and obesity in Brazilian individuals. Arch Endocrinol Metabol. 2017;61(5):438-446. doi:10.1590/2359-3997000000254

31. Saukkonen T, Mutt SJ, Jokelainen J, et al. Adipokines and inflammatory markers in elderly subjects with high risk of type 2 diabetes and cardiovascular disease. Sci Rep. 2018;8(1):12816. doi:10.1038/ s41598-018-31144-8

32. Rashad N, El-Shabrawy RM, Sabry HM, et al. Interleukin-6 and hs-CRP as early diagnostic biomarkers for obesity-related peripheral polyneuropathy in non-diabetic patients. Egypt J Immunol. 2018;25 (2):153-165.

33. Rehman K, Akash MSH, Liaqat A, et al. Role of Interleukin-6 in development of insulin resistance and Type 2 diabetes mellitus. Crit Rev Eukaryot Gene Expr. 2017;27(3):229-236. doi:10.1615/ CritRevEukaryotGeneExpr.2017019712

34. Klisic A, Kavaric N, Vujcic S, et al. Factorial analysis of the cardiometabolic risk influence on redox status components in adult population. Oxid Med Cell Longev. 2021;2021:6661940. doi:10.1155/2021/6661940

35. Leite M, Dutra MT, da Costa MVG, et al. Comparative evaluation of inflammatory parameters and substitute insulin resistance indices in elderly women with and without type 2 diabetes mellitus. Exp Gerontol. 2021;150:111389. doi:10.1016/j.exger.2021.111389

\section{Publish your work in this journal}

Diabetes, Metabolic Syndrome and Obesity: Targets and Therapy is an international, peer-reviewed open-access journal committed to the rapid publication of the latest laboratory and clinical findings in the fields of diabetes, metabolic syndrome and obesity research. Original research, review, case reports, hypothesis formation, expert opinion and commentaries are all considered for publication. The manuscript management system is completely online and includes a very quick and fair peer-review system, which is all easy to use. Visit http://www.dovepress.com/testimonials.php to read real quotes from published authors. 